\title{
Topical Application Of Fluoride In Patients Undergoing Orthodontic Treatment - A Retrospective Study
}

Research Article

Ashfaq Ahmed $\mathrm{M}^{1}$, Sri Rengalakshmi ${ }^{*}$, Saravana Dinesh. S.P ${ }^{3}$

${ }^{1}$ Saveetha Dental College and Hospitals, Saveetha Institute of Medical and Technical Sciences, Saveetha University, Chennai, India.

${ }^{2}$ Senior Lecturer, Department of orthodontics and Dentofacial Orthopedics, Saveetha Dental College and Hospitals, Saveetha Institute of Medical and Technical Sciences, Saveetha University, Chennai, India.

${ }^{3}$ Head of the Department, Department of Orthodontics and Dentofacial Orthopedics, Saveetha Dental College and Hospitals, Saveetha Institute of Medical and Technical Sciences, Saveetha University, Chennai, India.

\section{Abstract}

\begin{abstract}
Malocclusions are not life threatening conditions, yet they cause psychological and social problems in a patient's life by affecting their oral tissues. The most common side effect of orthodontic treatment is that they cause changes in the oral flora due to formation of non cleanable surfaces. Fluoride application has been associated with prevention of carious lesions in oral cavities. Thus the aim of the study was to analyse the use of topical fluoride application in patients undergoing orthodontic treatment. A retrospective analysis was done using dental archiving software present in saveetha dental college where details of 700 patients intraoperative photographs were checked for cross verification. The study was followed after the ethical approval of retrospective analysis by saveetha research board. Results were analysed and tabulated using chi square test. It is observed that most of the patients don't use topical fluoride application as a preventive measure prior to orthodontic treatment. Within the limits of this study of application of fluoride, patients of age group 10-25 years $(9.3 \%)$ are the predominant age group to undergo topical application of fluoride than other age groups and majority of the males $(8.3 \%)$ had undergone topical fluoride application than the females $(5.15 \%)$. From this we can conclude that only younger individuals are advised by their dentists for topical application of fluoride and older people should also be advised for fluoride application.
\end{abstract}

Keywords: Malocclusion; Fluoride; Carious Lesion; Bond Strength; APF.

\section{Introduction}

Malocclusions are not life-threatening conditions; however, they can affect the health of oral tissues and may cause psychological and social problems [1]. Nonalignment of the teeth on the jaws may cause dental caries due to the accumulation of dental plaques resulting from difficult-to-reach areas in the mouth [2]. For this reason, dental caries is seen as an important side effect of malocclusions. The common goal of all orthodontic treatment methods is to ensure that the teeth are aligned properly on the jaws, as well as in harmony with each other [3]. A balanced soft tissue appearance and an esthetic smile are virtually the greatest passion of patients and orthodontists [4]. The most common side effect of orthodontic treatments is that they cause changes in oral flora due to the formation of non-cleanable surfaces, and there- fore they cause areas of decalcification on the enamel and eventually periodontal diseases [5]. Appliances are directly attached to the tooth surface increasing the difficulty of achieving adequate oral hygiene. Some commonly used accessories, such as hooks, posts, elastic chains and springs, can also undermine dental biofilm removal. In orthodontics, the use of Bisphosphonates has been suggested as possible means to control relapse and even to generate "pharmacological anchorage" [6]. The lack of patient's cooperation and consequent poor oral hygiene is one of the main challenges in orthodontic practice. Bonding has been an area of paramount interest in Orthodontic research ever since the introduction of acid etching technique by Buonocore in 1955. There are many factors that can potentially affect the bond strength between the enamel and the orthodontic bracket including: the type of enamel conditioner, acid concentration, length of etching time, composition of the adhesive, bracket base design, the

*Corresponding Author:

Sri Rengalakshmi,

Senior Lecturer, Department of orthodontics and Dentofacial Orthopedics, Saveetha Dental College and Hospitals, Saveetha Institute of Medical and Technical Sciences, Saveetha

University, Chennai, India.

Tel: 8867783552

E-mail: srirengalakshmi.sdc@saveetha.com

Received: October 07, 2020

Accepted: November 22, 2020

Published: November 25, 2020

Citation: Ashfaq Ahmed M, Sri Rengalakshmi, Saravana Dinesh. S.P. Topical Application Of Fluoride In Patients Undergoing Orthodontic Treatment - A Retrospective Study. Int J Dentistry Oral Sci. 2020;7(11):1099-1102. doi: http://dx.doi.org/10.19070/2377-8075-20000218

Copyright: Sri Rengalakshmi ${ }^{\circ} 2020$. This is an open-access article distributed under the terms of the Creative Commons Attribution License, which permits unrestricted use, distribution and reproduction in any medium, provided the original author and source are credited. 
bracket material, the oral environment as well as the skill of the clinician. The shear bond strength of attachments indicates the retentive strength of the bracket on the tooth and should be sufficient to withstand forces of mastication and stress from arch wires and other force delivery system [7]. Transbond XT, a conventional light cured Bis-GMA based composite resin has been the popular material of choice in Orthodontic bonding today [8]. Instron testing machine is a highly sophisticated and technique sensitive equipment and has been used extensively in orthodontics for studies on bond strength, frictional resistance etc. It is comparatively less expensive, small in size and does not require expert handling [9].

The crystalline structure of enamel becomes more stable by the acquisition of fluoride which displaces the hydroxyapatite crystals to form fluoro apatite crystals [10]. It has been demonstrated that topical fluoride application induces deposition of calcium fluoride-like material ( $\mathrm{CaF} 2)$ on enamel surfaces. $\mathrm{CaF} 2$ remains available on enamel and in the dental biofilm during weeks after the orthodontic treatment starts [11]. APF gel is the most commonly used in dental practice where the patient is advised to not rinse or gargle for 30 min. It includes $1.23 \% \mathrm{NaF}$ and $1 \%$ sodium dihydrogen phosphate monohydrate [12]. The fluoride concentration of toothpastes should be over 1000 ppm and toothpastes with higher fluoride concentrations are more effective. Daily use of high-fluoride toothpastes can significantly reduce the prevalence and incidence of enamel lesions during the treatment of adolescents with fixed orthodontic appliances [13]. Thus the aim of the study was to analyse the prevalence of use of topical fluoride application in patients undergoing orthodontic treatment.

\section{Materials And Methods}

A single centre retrospective study was done in an institutional setting. The ethical approval was received from the institutional ethical committee. The study involved selected patients data who had undergone topical application of fluoride prior to orthodontic treatment. The necessary approvals in gaining the data were obtained from the institutional ethical committee (SDC/ SIHEC/2020/DIASDATA/0619-0320) The number of people involved in the study include guide, reviewer and researcher.

\section{Selection of Subjects}

All patients who had undergone topical application of fluoride from the time period of june 2019 to april 2020 were selected for the study $(\mathrm{N}=700)$. All available data were taken into consideration and there was no sorting process.

\section{Data collection}

The patient's details were retrieved from the institution's patient record management software (Dental information archiving software). Data regarding patients age, gender, topical application of fluoride were taken into consideration for this study. Cross verification was done with the help of photographs and radiographs. The data was manually verified, tabulated and sorted.

\section{Inclusion criteria}

All patients with fluorosis were taken into account.

\section{Exclusion criteria}

Patients' records that were incomplete were removed from the study. Repetitive entries were also removed. Patients who had systemic illness, multiple missing teeth, developmental anomalies, stains, multiple carious teeth were also excluded from the study.

\section{Statistical analysis}

The tabulation of data was analysed using SPSS software (IBM SPSS Statistics version 23.0). The method of statistical analysis that was used in this study was Chi square test to compare two proportions. The analysis was done for age, gender, presence/ absence of fluorosis in this study.

\section{Result And Discussion}

Early carious lesions are first seen as white spots in caries-susceptible locations around bracket margins and in the gingival third of teeth in patients undergoing orthodontic care. White-spot lesions are not unique to orthodontic patients alone and have been observed in $3 \%$ to $82 \%$ of children who have not received orthodontic treatment. In an effort to prevent the occurrence of whitespot lesions, a regimen for self-applied topical fluoride preparations is indicated in overall orthodontic treatment and may very well represent the standard of care in the orthodontic community. It becomes advantageous that a 1- step fluoride regimen be implemented as an adjunct toward clinical care [14].

From the study conducted above, it is found that among the 700 patients who were selected, 94 patients $(13.45 \%)$ had undergone fluoride application prior to the commencement of orthodontic treatment and 605 patients $(86.55 \%)$ had not undergone fluoride application (Figure 1).

We can also observe that the majority of the patients don't use topical fluoride application as a preventive measure prior to orthodontic treatment. Among the 94 patients who underwent fluoride application procedure, 65 patients $(9.30 \%)$ in the age group of 10-25 years had undergone fluoride application procedure and 29 patients $(4.15 \%)$ in the age group of $25-35$ years had undergone fluoride application procedure and no patients had undergone fluoride application procedure in the age group of 35-60 years (Figure 2). The results obtained are statistically significant $(\mathrm{p}<0.05)$.

It's also observed from our study that among the 94 patients who underwent fluoride application procedure, 58 males $(8.30 \%)$ had undergone topical application of fluoride when compared to female patients where 36 patients $(5.15 \%)$ had undergone topical application of fluoride prior to orthodontic treatment and the results obtained are statistically not significant $(\mathrm{p}>0.05)$ (Figure 3). A study conducted by Wang et al on bonding strength of brackets on the enamel on patients with tooth treated with fluoride and patients not treated with fluoride application proves that there is no statistical significant difference between the bonding strength [15]. However another study conducted by Noyes et al proves that pre-treatment is recommended for the reduction of caries and enamel decalcification and repeated fluoride applications to be done after bracketing is necessary whereas in our study, major- 
Figure 1. Bar graph represents number of patients who underwent topical application of fluoride. $\mathrm{X}$-axis represents fluoride application and Y-axis represents the total number of patients. Among 700 patients, 94 patients(13.45\%) had undergone fluoride application.

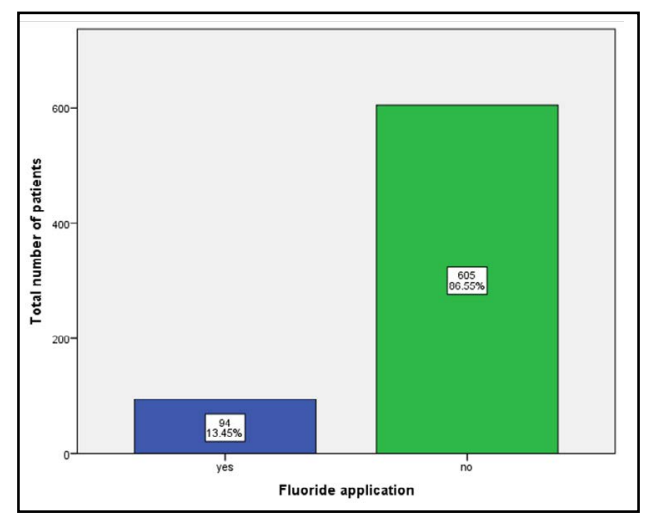

Figure 2. Bar graph represents association between age and topical application of fluoride. X-axis represents the age group and $\mathrm{Y}$-axis represents the total number of patients. Majority of the patients in the age group of 10-25 years had undergone topical application of fluoride prior to orthodontic treatment.. (Chi square test, p-value: $0.047(\mathrm{p}<0.05)$ statistically significant).

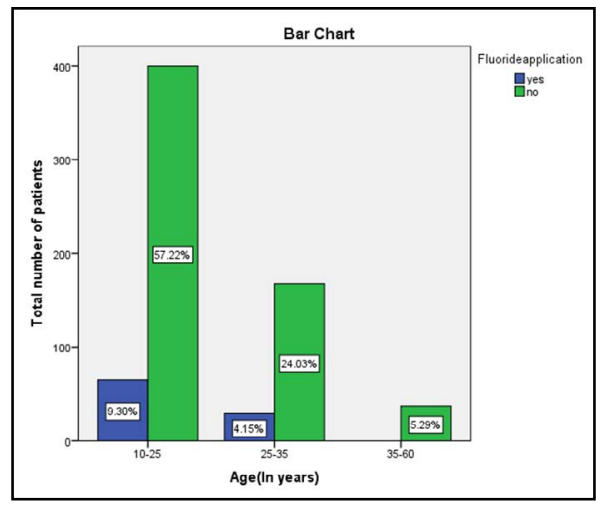

Figure 3. Bar graph represents association between age and topical application of fluoride. X-axis represents the age group and $\mathrm{Y}$-axis represents the total number of patients. Majority of the males $(8.30 \%)$ had undergone topical application of fluoride prior to orthodontic treatment when compared to females $(5.15 \%)$. (Chi square test, $\mathrm{p}$-value: $0.156(\mathrm{p}<0.05)$ statistically significant).

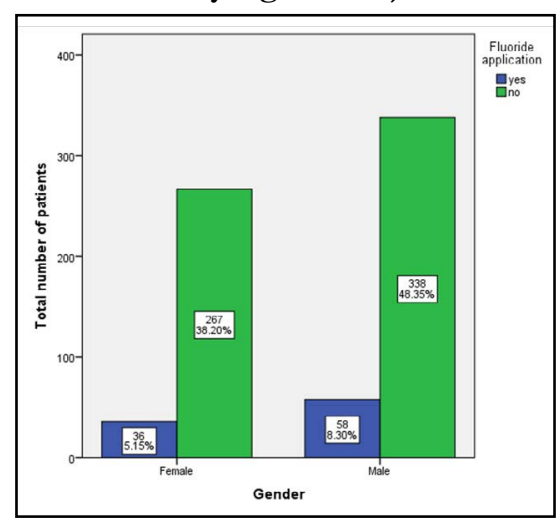

ity of the subjects do not use fluoride application prior to ortho treatment [16]. The results of the study done by alexander et al show that the daily use of a 5000- ppm fluoride gel along with conventional toothbrushing with an over-the-counter fluoride toothpaste or the twice daily use of a $5000 \mathrm{ppm}$ gel dentifrice is significantly more effective in preventing demineralization than the use of toothpaste and mouth rinsing with a $0.05 \%$ fluoride solution [14]. Confocal microscope evaluation showed that enamel conditioning with $37 \%$ phosphoric acid produced greater depths of resin penetration than did self-etching primer or air abrasion [17]. The limitations of the study were that it is a unicentered study with predominant south indian population with inadequate sample size. The study can be further elaborated with a large population and conducting clinical trials with different types of fluorides to ensure the effectiveness of the study. Previously our team had conducted numerous clinical trials [18-21] and lab animal studies [22-24] and in vitro studies [25-27] over the past 5 years. Now we are focussing on epidemiological studies. The idea for this study stemmed from the current interest in our community. It is important that the health care workers educate the patients about fluoride application and its advantages before undergoing orthodontic treatment to minimise the effect of brackets on the enamel and thus giving a pleasing smile after the completion of the treatment. 


\section{Conclusion}

Within the limits of this study of application of fluoride, age groups of 10-26 years are the predominant group to undergo topical application of fluoride and majority of the males had undergone topical fluoride application than the females. Thus it is important to make the patients understand about the significance of topical fluoride application before undergoing orthodontic treatment which can make the teeth caries resistant.

\section{Acknowledgement}

The authors would like to thank Saveetha Dental College and Hospitals for providing the platform to conduct the study.

\section{References}

[1]. Taylor KR, Kiyak A, Huang GJ, Greenlee GM, Jolley CJ, King GJ. Effects of malocclusion and its treatment on the quality of life of adolescents. Am J Orthod Dentofacial Orthop. 2009 Sep 1;136(3):382-92.

[2]. Feldens CA, Dos Santos Dullius AI, Kramer PF, Scapini A, Busato AL, Vargas-Ferreira F. Impact of malocclusion and dentofacial anomalies on the prevalence and severity of dental caries among adolescents. Angle Orthod. 2015 Nov;85(6):1027-34.Pubmed PMID: 26516712.

[3]. Gaikwad SS, Gheware A, Kamatagi L, Pasumarthy S, Pawar V, Fatangare M. Dental caries and its relationship to malocclusion in permanent dentition among 12-15 year old school going children. J Int Oral Health. 2014 Sep;6(5):27-30.Pubmed PMID: 25395789.

[4]. Hafez HS, Shaarawy SM, Al-Sakiti AA, Mostafa YA. Dental crowding as a caries risk factor: a systematic review. Am J Orthod Dentofacial Orthop. 2012 Oct;142(4):443-50.Pubmed PMID: 22999666.

[5]. Sonesson M, Twetman S, Bondemark L. Effectiveness of high-fluoride toothpaste on enamel demineralization during orthodontic treatment-a multicenter randomized controlled trial. Eur J Orthod. 2014 Dec;36(6):678-82. Pubmed PMID: 24375756

[6]. Krishnan S, Pandian S, Kumar S A. Effect of bisphosphonates on orthodontic tooth movement-an update. J Clin Diagn Res. 2015 Apr;9(4):ZE01-5. Pubmed PMID: 26023659.

[7]. Kamisetty SK, Verma JK, Arun, Sundari S, Chandrasekhar S, Kumar A. SBS vs Inhouse Recycling Methods-An Invitro Evaluation. J Clin Diagn Res. 2015 Sep;9(9):ZC04-8.Pubmed PMID: 26501002.

[8]. Samantha C, Sundari S, Chandrasekhar S, Sivamurty G, Dinesh S. Comparative Evaluation of Two Bis-GMA Based Orthodontic Bonding Adhesives - A Randomized Clinical Trial. J Clin Diagn Res. 2017 Apr;11(4):ZC40ZC44.Pubmed PMID: 28571259.

[9]. Dinesh SP, Arun AV, Sundari KK, Samantha C, Ambika K. An indigenously designed apparatus for measuring orthodontic force. J Clin Diagn Res. 2013 Nov;7(11):2623-6.Pubmed PMID: 24392423.

[10]. Wiechmann D, Klang E, Helms HJ, Knösel M. Lingual appliances reduce the incidence of white spot lesions during orthodontic multibracket treatment. Am J Orthod Dentofacial Orthop. 2015 Sep;148(3):414-22.Pubmed PMID: 26321339.
[11]. Gontijo L, Cruz Rde A, Brandão PR. Dental enamel around fixed orthodontic appliances after fluoride varnish application. Braz Dent J. 2007;18(1):4953.Pubmed PMID: 17639201.

[12]. Miura KK, Ito IY, Enoki C, Elias AM, Matsumoto MA. Anticariogenic effect of fluoride-releasing elastomers in orthodontic patients. Braz Oral Res. 2007 Jul-Sep;21(3):228-33.Pubmed PMID: 17710288.

[13]. Benson PE, Parkin N, Dyer F, Millett DT, Furness S, Germain P. Fluorides for the prevention of early tooth decay (demineralised white lesions) during fixed brace treatment. Cochrane Database Syst Rev. 2013 Dec 12;(12):CD003809.Pubmed PMID: 24338792.

[14]. Alexander SA, Ripa LW. Effects of self-applied topical fluoride preparations in orthodontic patients. Angle Orthod. 2000 Dec;70(6):424-30.Pubmed PMID: 11138645.

[15]. Wang WN, Sheen DH. The effect of pretreatment with fluoride on the tensile strength of orthodontic bonding. Angle Orthod. 1991 Spring;61(1):31-4. Pubmed PMID: 1826416.

[16]. Noyes HJ. Dental Caries and the Orthodontic Patient. The Journal of the American Dental Association and The Dental Cosmos. 1937 Aug $1 ; 24(8): 1243-54$.

[17]. Ramesh Kumar KR, Shanta Sundari KK, Venkatesan A, Chandrasekar S. Depth of resin penetration into enamel with 3 types of enamel conditioning methods: a confocal microscopic study. Am J Orthod Dentofacial Orthop. 2011 Oct;140(4):479-85.Pubmed PMID: 21967934.

[18]. Sivamurthy G, Sundari S. Stress distribution patterns at mini-implant site during retraction and intrusion--a three-dimensional finite element study. Prog Orthod. 2016;17:4.Pubmed PMID: 26780464.

[19]. Vikram NR, Prabhakar R, Kumar SA, Karthikeyan MK, Saravanan R. Ball Headed Mini Implant. J Clin Diagn Res. 2017 Jan;11(1):ZL02-3.

[20]. Viswanath A, Ramamurthy J, Dinesh SP, Srinivas A. Obstructive sleep apnea: awakening the hidden truth. Niger J Clin Pract. 2015 Jan-Feb;18(1):1-7. Pubmed PMID: 25511335.

[21]. Felicita AS. Quantification of intrusive/retraction force and moment generated during en-masse retraction of maxillary anterior teeth using mini-implants: A conceptual approach. Dental Press J Orthod. 2017 SepOct;22(5):47-55.Pubmed PMID: 29160344.

[22]. Rubika J, Felicita AS, Sivambiga V. Gonial angle as an indicator for the prediction of growth pattern. World J Dent. 2015;6(3):161-3.

[23]. Jain RK, Kumar SP, Manjula WS. Comparison of intrusion effects on maxillary incisors among mini implant anchorage, j-hook headgear and utility arch. J Clin Diagn Res. 2014 Jul;8(7):ZC21-4.Pubmed PMID: 25177631.

[24]. Pandian KS, Krishnan S, Kumar SA. Angular photogrammetric analysis of the soft-tissue facial profile of Indian adults. Indian J Dent Res. 2018 MarApr;29(2):137-143.Pubmed PMID: 29652003.

[25]. Felicita AS. Orthodontic management of a dilacerated central incisor and partially impacted canine with unilateral extraction - A case report. Saudi Dent J. 2017 Oct;29(4):185-193.Pubmed PMID: 29033530.

[26]. Felicita AS, Chandrasekar S, Shanthasundari KK. Determination of craniofacial relation among the subethnic Indian population: a modified approach - (Sagittal relation). Indian J Dent Res. 2012 May-Jun;23(3):305-12. Pubmed PMID: 23059564.

[27]. Felicita AS. Orthodontic extrusion of Ellis Class VIII fracture of maxillary lateral incisor - The sling shot method. Saudi Dent J. 2018 Jul;30(3):265269.Pubmed PMID: 29942113. 